\title{
Determining the Mistakes of Secondary School Mathematics Teachers in Operation Priority
}

\author{
Tayfun TUTAK* \\ Mathematics Education, Firat University, Elazığ, Turkey \\ ORCID: 0000-0002-0277-6377 \\ Ahmet Burak SÜZEN \\ Mathematics Education, Ministry of National Education, Elazı̆̆, Turkey \\ ORCID: 0000-0002-8996-1769 \\ İbrahim Enam INAN \\ Mathematics Education, Firat University, Elazığ, Turkey \\ ORCID: 0000-0003-3681-0497
}

Article history

Received:

16.09.2019

Received in revised form: 11.12.2019

Accepted:

15.12.2019

Key words:

Mathematics Teaching,

Operation priority (Order-of-

Operations), Four operations,

Mistake
The aim of this study is to determine the mistakes made by secondary school mathematics teachers in the operation priority (Order-ofOperations) and to offer solutions to these problems. The research, which is conducted during 2018-2019 academic year in the central district of Elazığ and is limited to fifteen mathematics teachers who had different professional experiences and differed in the departments they graduated from. A form which prepared by experts of the field and consisting of 5 open-ended questions was given to the teachers to get their views on the order of operations. Interview technique was used to determine the knowledge levels of teachers in this qualitative study. Semi-structured interview form was used as data collection tool. Qualitative research method was preferred for collecting, analyzing and interpreting the data of this research. Data analysis and interpretation were based on content analysis method which is among the methods of qualitative research designs. The results are presented in a descriptive manner. According to the results of the research, it is revealed that teachers do not fully know the operation priority rule. Based on the findings and results of the current research, some pedagogical and theoretical implications are presented with a view to enlightening the practitioners and researchers.

\section{Introduction}

Mathematics is a science built on numbers and shapes that have been needed ever since humanity has existed (Ülger, 2005). The basic building blocks of mathematics are numbers and operations. Numbers allow us to answer questions such as "how many" and "how much" in daily life (Cengiz, 2013). Mathematical expressions are created according to certain rules. Operation priority is one of these rules. In order to perform mathematical calculations involving more than one operation, the necessary rules are called as "operation priority". In the operation priority rule, which is commonly encountered in arithmetic and algebraic calculations, a sequence of exponential expressions, multiplication / division and addition / subtraction is

\footnotetext{
*Correspondency: tayfuntutak@ hotmail.com
} 
followed, starting with parenthetical expressions (Öcal, İpek, Özdemir, Kar, 2018). For example, in the expression 9-2x4, the multiplication is done before subtraction and the answer is found as 1. However, in an expression that includes both division and multiplication, the operation priority starts from the left-hand operation. For example, in $12 \div 4 \times 2$, the division on the left is done first, and the result is 6 . According to these rules, the order of operation is sorted as; parentheses, exponential expressions, multiplication / division and addition / subtraction.

- Operations and the relationships between operations begin to be taught from primary school. The change and development of inter-operation characteristics is also important for secondary school mathematics education and training. One of the basic rules we use most when doing operations is operation priority. The operation appears on arithmetic in mathematics and it is a topic that cannot be delimited by just one subject and has its reflections on the operation dimension of each subject. When the studies about the operation priority were examined (Yenilmez, 2018), it was found that the students had difficulties in learning the operation priority rule. Particularly on the 5th and 6th grades, it is necessary to be very careful about presenting the operation priority found in the curriculum and to take into consideration the level of readiness of the students when giving the order of the operation priority (Yenilmez, 2018). Because the issue of integers is not yet known at this level, in particular, the operation priority of addition and subtraction operations are identical and that we can choose whichever we want as one of these two operations has no operation priority over the other and, after being told that they can start from their desired one, students may think that the question is wrong, especially when they see examples where a larger number is subtracted from a small number. The mathematics teacher who teaches at this level is required to explain this situation by taking into consideration and in fact leaving the general rules and patterns aside. Another problem encountered is with the multiplication and division. After telling students that multiplication and division count the same in the operation, they can find different results as in the example below.

Example: What is the result of $200 \div 10 \times 2$ operation?

Student 1) $20 \times 2=40$

Student 2) $200 \div 20=10$

The above random two students are likely to find different results after the teacher's explanation: "You can choose any of the multiplication and division operations." In that case, the teacher teaching the mathematics class at secondary level should take the relevant rules into account and adjust these to the level of the student. The failure to learn the sequence and rules regarding the operation priority is not due to the difficulty of the subject but related to the rules' being explained in narrow patterns and differently (Süzen, 2019). Indeed, this subject is explained in an incomplete fashion even in the books published by the Ministry of National Education every year. The book, which was published a year ago i.e. for the 2017-2018 academic year, assures that parentheses should be handled first yet in the newly published book in the 2018-2019 academic year, it is stated that the first place is to be the exponential numbers in the operation priority (MEB, 2019). Therefore, a contradiction occurs here. In a study about the order-of-operations in arithmetic operations, it was emphasized that the operational and conceptual model should not be overlooked especially in mathematics education by mentioning the Peano Axioms. Besdies, in this study, he stated that this situation was ignored in the 
mathematics curriculum and that instead of spending time on the essence of mathematics, the definition of numbers and a series of unnecessary rules were imposed. Finally, the practitioner of the teaching activities in the field made some recommendations to the teachers (İlgün, Elmas \& Küçük, 2017).

When the studies on this subject were examined, it was found that these concentrated generally upon the framework of the detection and interpretation of the errors made in the four operations and most of the work was about students (Akkan, Cakiroglu and Guven, 2008; Brown and Burton, Chick and Baker, 2005; 1978; Dede and Peker, 2007; Dinc Artut and Tarım, 2006; Dogan, 2002; Engelhardt, 1977; Govindan and Ramaa, 2013; Kubanc, 2012; Önal, 2018; Varol and Kubanç, 2015; Yorulmaz, 2018). However, a study on operation priority with teachers who are the agents does not seem to appear in the literature. It is thought that this research will eliminate this deficiency in the literature. Therefore, the problem statement of the research is formed as, "What are the mistakes made by secondary school mathematics teachers in the operation priority?".

\section{Method}

\section{Research Model}

In this research, qualitative research method was adopted. The aim of qualitative research is to investigate in depth an event or organization, rather than a superficial screening of a population. In this research, interview method was used. Interview method is the most commonly used data collection tool confronted in qualitative research. In order for the interview to be used as an effective and efficient data collection method, it is necessary to understand the basic features, strengths and weaknesses of this method well and to assimilate the principles recommended in the process of preparing an interview form (Yıldırım \& Şimşek, 2008).

\section{Working Group}

In qualitative studies, the characteristics of the research and the resources of the researcher are important in the selection of the sample (Yıldırım \& Şimşek, 2008). One of the purposeful sampling methods called criterion sampling, was used in the determination of the study group. Purposeful sampling is used to be able to determine in depth the situations thought to have rich information. Büyüköztürk et al. (2012) stated that criterion sampling consists of events, persons, objects or situations with the specified qualifications related to the problem.

The size of the sample is an important problem in qualitative research. There are no rules regarding the size of the sample. The size of the sample depends on what we want to know, the purpose of the researcher, what will be useful, what will be reliable and what can be done over the resources and time available (Patton, 2014).

In this research, the study group was determined as 15 secondary school mathematics teachers working in the central district of Elâzı ğ province in the spring term of 2018-2019 academic year. Teachers were chosen on a voluntary basis in the study. The teachers participating in the study were coded as $\mathrm{T} 1, \mathrm{~T} 2, \mathrm{~T} 3, \ldots, \mathrm{T} 15$. No personal information was requested from any mathematics teacher and it was not used in the content of the study within the scope of the study ethics. Demographic characteristics of the participants are given in Table 1 below. 
Table 1. Demographic Characteristics of Participants in the Thesis Research

\begin{tabular}{lll} 
& Graduated Faculty or High school & Professional experience \\
\hline T1 & Faculty of Education & $1-5$ Years \\
T2 & Faculty of Education & $1-5$ Years \\
T3 & Faculty of Education & $1-5$ Years \\
T4 & Faculty of Education & $6-10$ Years \\
T5 & Faculty of Education & $6-10$ Years \\
T6 & Faculty of Education & $6-10$ Years \\
T7 & Faculty of Education & $11-15$ Years \\
T8 & Faculty of Education & $11-15$ Years \\
T9 & Faculty of Education & $11-15$ Years \\
T10 & Faculty of Science and Literature & $16-20$ Years \\
T11 & Faculty of Science and Literature & $16-20$ Years \\
T12 & Faculty of Education & $16-20$ Years \\
T13 & Faculty of Education & Over 20 Years \\
T14 & Faculty of Education & Over 20 Years \\
T15 & Faculty of Science and Literature & Over 20 Years \\
\hline
\end{tabular}

\section{Data Collection Tools}

In the research, semi-structured interview form was used which was developed by the researcher. Prior to the preparation of the interview questions, literature review was carried out at domestic and international levels by examining the existing studies and bulk of research. Three mathematics teachers were told about the subject and their approaches to the subject were evaluated during the construction of the current study. Two academicians working on a similar topic were consulted, interview forms were obtained used in their research. As a result of the literature review, and in light of the mathematics teachers' approaches towards the subject and bearing in mind the data obtained from two academicians who conducted similar studies in Turkey, an interview form was prepared. Open-ended questions were asked in the interview form and these questions were formed by adhering to the sub-problems of the research. This interview form was presented to the opinion of five different experts (1 Measurement and Evaluation Specialist, 2 Education Specialists and 2 Mathematics educators) in order to ensure the scope validity of the study. After the suggestions and the necessary changes, the questions were applied to five mathematics teachers who were not included in the study group in order to determine the scope validity and reliability. It was concluded that the questions prepared as a result of the examination exactly represent the subject.

Semi-structured interview forms were used to ensure that the interviewees express themselves well (Büyüköztürk et al., 2012) for in semi-structured interviews, a series of questions are prepared to be used in all interviews. A semi-structured interview technique is actually a form of interview where all interviewees are asked questions in the same order and all are allowed to answer the questions as they wish (Yıldırım \& Şimşek, 2006).

The semi-structured interview technique aims to obtain information thoroughly. This technique has advantages such as being easy to analyze, enabling oneself to express themselves better, arranging questions according to the course during the interview (Ekiz, 2003). Therefore, in this study, semi-structured interview technique was preferred in order to determine the mistakes of teachers about four operations. 


\section{Data Analysis}

The data obtained from the research were analyzed by content analysis method. Content analysis paves the way for an objective and systematic examination of verbal, written and other materials (Tavşancil \& Aslan, 2001). In the study, interview forms were read and coded after being transferred to computer. Categories were created from these codes. According to the responses of the interviewers, frequencies and percentages of the codes and categories were determined. These frequencies were arranged and made into tables to facilitate interpretation.

\section{Findings}

In this section, the findings are given in tables and comments are made according to the tables. Descriptive statistics were used to analyze the mistakes of secondary school mathematics teachers in operation priority.

Opinions on the priority of the operation; "In what order do you tell the students they should perform the operations?"

Table 2. Teachers' Answers to the First Question and Percentage, Frequency Value

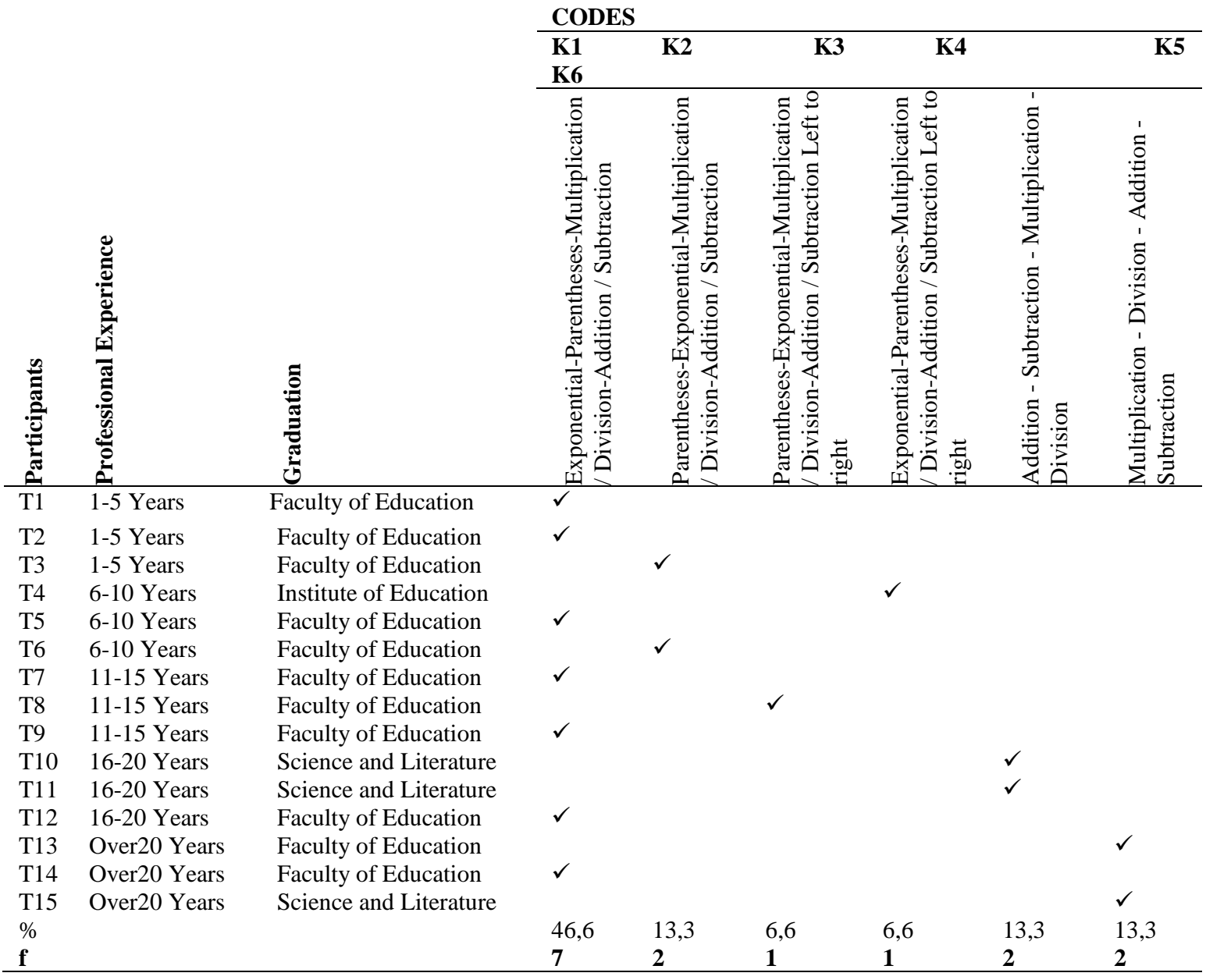

Teachers participating in the research stated that they presented the operation priority rule $46,6 \% \mathrm{~K} 1,13,3 \% \mathrm{~K} 2,6,6 \% \mathrm{~K} 3,6,6 \% \mathrm{~K} 4,13,3 \% \mathrm{~K} 513.3 \%$ of them according to $\mathrm{K} 6$, respectively.

Opinions on the question: "From which source do you describe the operation priority?" 
Table 3. Teachers' responses to the second question and the resulting frequency, percentage values.

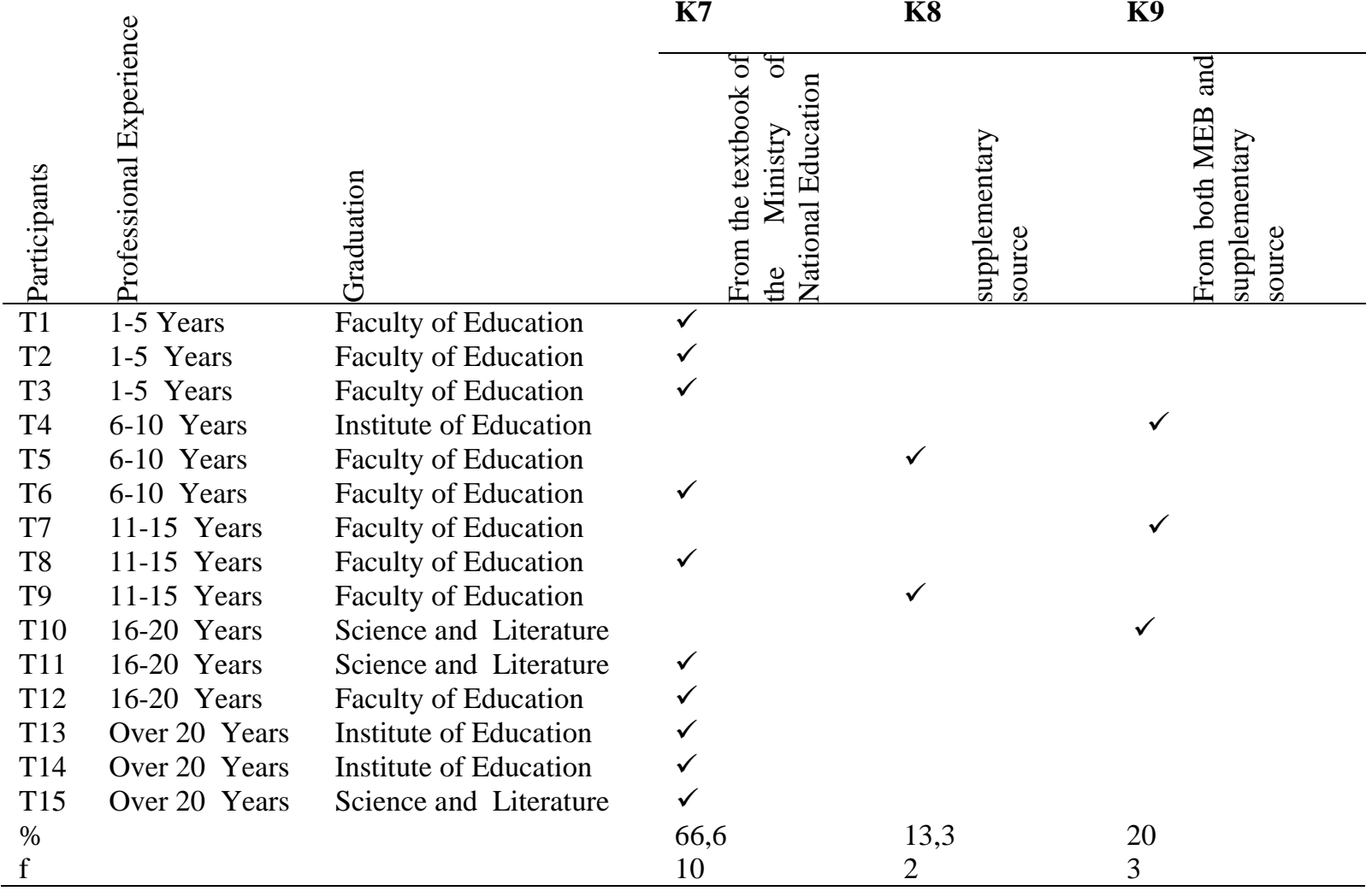

CODES

$66.6 \%$ of the teachers who participated in the research stated that they explained the subject from the textbooks of the Ministry of National Education, $13.3 \%$ stated that they explained the subject from supplementary sources and $20 \%$ from both sources.

Opinions on the question: "Which operation has the priority; division and multiplication or addition and subtraction in the operation priority?"

Table 4. Teachers' responses to the third question and the resulting frequency, percentage value

\begin{tabular}{|c|c|c|c|c|c|}
\hline \multirow[b]{3}{*}{ 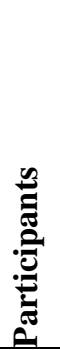 } & \multirow[b]{3}{*}{ 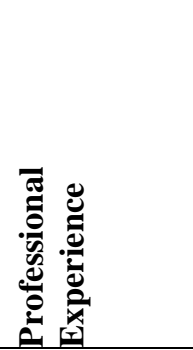 } & \multirow[b]{3}{*}{ Graduation } & \multicolumn{3}{|c|}{ CODES } \\
\hline & & & K10 & K11 & K12 \\
\hline & & & 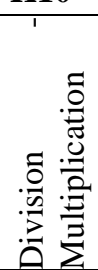 & 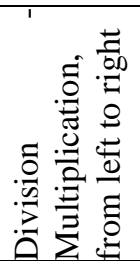 & 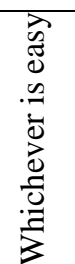 \\
\hline $\mathrm{T} 1$ & 1-5 Years & Faculty of Education & & & $\checkmark$ \\
\hline $\mathrm{T} 2$ & 1-5 Years & Faculty of Education & & $\checkmark$ & \\
\hline T3 & 1-5 Years & Faculty of Education & $\checkmark$ & & \\
\hline $\mathrm{T} 4$ & 6-10 Years & Institute of Education & $\checkmark$ & & \\
\hline T5 & 6-10 Years & Faculty of Education & $\checkmark$ & & \\
\hline T6 & 6-10 Years & Faculty of Education & & $\checkmark$ & \\
\hline $\mathrm{T} 7$ & 11-15 Years & Faculty of Education & & $\checkmark$ & \\
\hline T8 & 11-15 Years & Faculty of Education & $\checkmark$ & & \\
\hline
\end{tabular}




$\begin{array}{lll}\text { T9 } & \text { 11-15 Years } & \text { Faculty of Education } \\ \text { T10 } & \text { 16-20 Years } & \text { Science and Literature } \\ \text { T11 } & \text { 16-20 Years } & \text { Science and Literature } \\ \text { T12 } & \text { 16-20 Years } & \text { Faculty of Education } \\ \text { T13 } & \text { Over 20 Years } & \text { Institute of Education } \\ \text { T14 } & \text { Over 20 Years } & \text { Institute of Education } \\ \text { T15 } & \text { Over 20 Years } & \text { Science and Literature } \\ \% & & \\ \text { f } & & \end{array}$

Faculty of Education

Science and Literature

Science and Literature

Faculty of Education

Institute of Education

Institute of Education

Science and Literature

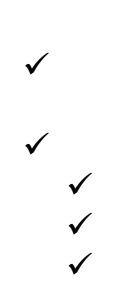

59,4
26,6

4
13,3

2

$59.6 \%$ of the participants said that division is done first and after that multiplication should be carried out, $26.6 \%$ of them said first division and after multiplication, but since there are two operations of the same type, operation is done from left to right, and lastly $13.3 \%$ of them said that operation is done from whichever is easy.

Opinions on the statement: "Solve $20+7 \div 35 \div 5$ according to the operation priority rule."

Table 5. Teachers' Answers to Fourth Question and Frequency, Percentage Value

\begin{tabular}{|c|c|c|c|c|}
\hline \multirow{3}{*}{ 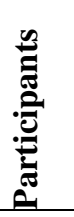 } & \multirow{3}{*}{ 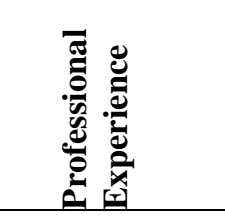 } & \multirow{3}{*}{ 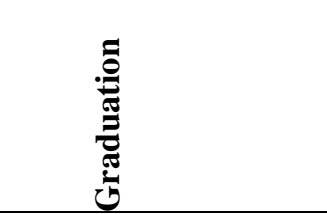 } & \multicolumn{2}{|c|}{ CODES } \\
\hline & & & K13 & K14 \\
\hline & & & 20,04 & 21 \\
\hline T1 & 1-5 Years & Faculty of Education & & $\checkmark$ \\
\hline $\mathrm{T} 2$ & 1-5 Years & Faculty of Education & & $\checkmark$ \\
\hline T3 & 1-5 Years & Faculty of Education & & $\checkmark$ \\
\hline $\mathrm{T} 4$ & 6-10 Years & Institute of Education & $\checkmark$ & \\
\hline T5 & 6-10 Years & Faculty of Education & $\checkmark$ & \\
\hline T6 & 6-10 Years & Faculty of Education & $\checkmark$ & \\
\hline $\mathrm{T} 7$ & 11-15 Years & Faculty of Education & $\checkmark$ & \\
\hline $\mathrm{T} 8$ & 11-15 Years & Faculty of Education & $\checkmark$ & \\
\hline T9 & 11-15 Years & Faculty of Education & $\checkmark$ & \\
\hline T10 & 16-20 Years & Science and Literature & & $\checkmark$ \\
\hline T11 & 16-20 Years & Science and Literature & & $\checkmark$ \\
\hline $\mathrm{T} 12$ & 16-20 Years & Faculty of Education & $\checkmark$ & \\
\hline $\mathrm{T} 13$ & Over 20 Years & Institute of Education & & $\checkmark$ \\
\hline T14 & Over 20 Years & Institute of Education & $\checkmark$ & \\
\hline T15 & Over 20 Years & Science and Literature & & $\checkmark$ \\
\hline$\%$ & & & 53,3 & 46,6 \\
\hline $\mathrm{f}$ & & & 8 & 7 \\
\hline
\end{tabular}

$53.3 \%$ of the teachers participating in the study found the result given with the K13 code, while $46.6 \%$ found the result coded with K14.

Opinions on the question: "If a student who is on the 6th grade without knowing the subject of integers was asked to give an answer to " $3-5+7$ " while operation priority is being presented and if the student said "this is faulty because the larger number cannot be subtracted from the smaller one", how would you answer, how would you explain the way to the solution to this problem?"

As the last question of the research, an open-ended question was asked. The teachers' answers to this question are as follows: 
- T1 and T3: I say that you have "+" before " 3 ". Then I make $3+7=10$ and show that $10-5=5$.

- T2: Since it is both addition and subtraction, I say that you can start from which one you wish.

- T4: Since the operation priorities are the same, they are added first and subtracted later.

- T5, T10, T11, T13 and T15: I teach the subject of integers.

- T6, T12, T13: First we add up the positives, then we subtract the negatives.

- T7: I say that the problem is not wrong, but to solve this question, one needs to know the addition and subtraction of integers and he will learn this on the 7th grade.

- T8: I first add up and then subtract the negatives and perform the subtraction.

- T9: I say that they will be presented with this subject in the future.

\section{Conclusion, Discussion}

\section{Conclusions about the First Question}

In the first question of the study, the participant teachers were asked the question "In which order do you present the students the operation priority?". The answers given by the teachers were evaluated and $\mathrm{K} 1, \mathrm{~K} 2, \mathrm{~K} 3, \mathrm{~K} 4, \mathrm{~K} 5$ and $\mathrm{K} 6$ codes were given to the answers. $46.6 \%$ were $\mathrm{K} 1,13.3 \%$ were $\mathrm{K} 2,6.6 \%$ were $\mathrm{K} 3,6.6 \%$ were $\mathrm{K} 4,13.3 \%$ were $\mathrm{K} 5$ and $13.3 \%$ of the 15 participating teachers presented the operation priority rule by K6. İlgün, Elmas and Küçük (2017) gave the priority within the operation as follows:

- Inside parentheses

- Exponentiation

- Multiplication and division from left to right

- Addition and subtraction from left to right.

Öksüz (2009, p. 307), in his study entitiled "teaching the order of operations", stated the standard of operation order as follows: "Expressions in parentheses are dealt with first; then Exponential Expressions, then Multiplication and Division; the last Addition and Subtraction operations are performed and all of them are executed from left to right".

The above described rule is given by the code K3 in the study. According to this, it is seen that only one of the 15 teachers (6.6\%) participated in the study gave the correct answer. T8, with 11-15 years of professional experience, answered this question correctly. However, since all the participants with 11-15 years of experience were graduates of the Faculty of Education, it cannot be said that there is a significant difference pertaining to the graduated faculty. From this it can be seen that the teachers participated in the research do not really know the rules of operation well. When the answers given by the teachers participating in the study were taken into consideration, no significant relationship was found between their professional experiences and graduation status.

\section{Conclusions about the second question}

For the second question, "From which source do you describe the operation priority?" was asked to the participants. Teachers' answers were coded as K7, K8 and K9. In the data coded with $\mathrm{K} 7$ code, the teachers explained the operation priority issue from the textbook of the 
Ministry of National Education, K8 code from supplementary source and K9 code stated that they explained the subject from both sources. 66.6\% of the participants stated that they explained the subject from the textbook of the Ministry of National Education, while 13.3\% stated that they explained the subject from the supplementary sources and $20 \%$ from both sources. The number of teachers who stated that they presented the subject from the National Education textbook was 10 out of the 15 teachers who participated in the research. That is to say, the majority of teachers use the textbook as the main source. This result is in line with Tutak and Güder's (2012) study named "Primary school 5th grade teachers' opinions and thoughts about mathematics textbook".

The 6th grade mathematics book of the Ministry of National Education, published in 2018-2019 academic year, describes the very subject as follows:

In cases where there is more than one operation, firstly exponential numbers, then operations in parentheses, then multiplication or division operations, and finally addition or subtraction operations are performed. Operations with the same priorities (multiplication or division, addition or subtraction) are performed from left to right, respectively.

In the 5th grade math book of the Ministry of National Education published in 2018-2019 academic year, the subject is explained as follows:

In cases where there are more than one operation, if there is a parenthesis, the operation within the parenthesis is done first.

When the above two books are examined, an inconsistency spotted between the 5th and 6th grade textbooks. The 6th grade textbook says that the exponential numbers will be considered before the parentheses. There are inconsistencies between the books published in the 20172018 academic year and even between the book published in the 2018-2019 academic year. This situation misled the teachers who explained the issue from the book of the Ministry of National Education and caused them to learn and teach wrongly. Kocaoğlu (2016), revealed the views of teachers about textbooks in his study which is named "The Views of Primary School Mathematics Teachers on 5th and 6th Grade Textbooks". The teachers stated that the textbooks are not suitable for the teaching and learning of the subject. This is similar to the results of this research.

$66.6 \%$ of the teachers participating in the research said that they were teaching the subject from the textbook of the Ministry of National Education may not reflect the reality. Even if there is an inconsistency between the parenthesis's operation and the exponential operation priority in the books of the Ministry of National Education, when the answers given by the participants are taken into account, it is seen that the participants did not examine these books and did not teach the subject from the textbook. Teachers with 1-5 years of professional experience and teachers with more than 20 years of professional experience all declare that they presented the subject in the textbook of the Ministry of National Education, but the wrong answer to the first sub-problem and the fourth sub-problem all constitute a discrepancy between teachers' answers. When the answers given by the teachers participating in the study were taken into consideration, no significant relationship was found between their graduation (educational) statuses. 


\section{Conclusions about the Third Question}

In the third question of the study, the participant teachers were asked "Which operation has the priority; division and multiplication or addition and subtraction in the operation priority?". The answers given by the teachers were evaluated and K10, K11 and K12 codes were given to the answers. 59.4\% stated that they taught the operation priority rule according to $\mathrm{K} 10,26.6 \% \mathrm{~K} 11$ and $13.3 \% \mathrm{~K} 12$ from the 15 participants participated to the study. İlgün, Elmas and Küçük (2017) used the following expressions for the same kind of operations in their work called "Arithmetic Operation Priority":

\section{"Multiply and divide from left to right. Add and subtract from left to right."}

While multiplication and division constitute priority over addition and subtraction, the same kind of operations are performed from left to right. This sequence was coded with K11. When the answers given by the participants were taken into consideration, $26.6 \%$ of them answered it correctly. That is, only 4 teachers out of the 15 teachers who took part in the research gave the correct answer. This shows that the teachers do not know which of the same kind of operations should be done first. All respondents who answered the third question correctly graduated from the Faculty of Education. If so, there is a meaningful difference between the graduation status and the rule by which the same type of operations will be performed during the operation. Two of the 3 respondents with 11-15 years of professional experience answered the question correctly, indicating a significant difference between those with 11-15 years of professional experience and others. The fact that no correct answers were obtained from the participants with 16 years or more of professional experience showed that there was an inverse relationship between professional experience and conceptual and operational knowledge possessed.

\section{Conclusions about the Fourth Question}

In the fourth question of the research, the participant teachers were asked to solve: "20 $+7 \div 35 \div 5$ " according to the operation priority rule. The answers given by the teachers were evaluated and K13 and K14 codes were given to the answers. While 53.3\% of the 15 participant teachers gave 20.04 answers coded with $\mathrm{K} 13$ code, $46.6 \%$ of them answered 21 answers coded with K14 code. In this case, almost half of the teachers answered the operational question correctly, while the other half gave the wrong answer. In the first sub-problem, although only one of the 15 participating teachers knew the order of operation correctly which is the conceptual information, it was revealed that 8 participant teachers correctly solved the operational information and that the teachers knew the operational information better than the conceptual information. The fact that the 8 participants who answered the fourth question correctly, 6 of them graduated from the Faculty of Education, revealed that there was a significant difference between the school and operational information. Among the participating teachers, the fact that no participant teacher who graduated from the Faculty of Arts and Sciences gave a correct answer demonstrated that there was a significant difference between the school that was graduated from and operational knowledge. The fact that no participant teacher with 1-5 years of professional experience correctly answered this question revealed that these participants had little expertise on the field. Correct answers of six teachers with professional experience of 6-10 and 11-15 years showed that knowledge increases as experience increases. However, the fact that only one participant with 16-20 years of professional experience and only one of the participants with more than 20 years of experience gave the correct answer indicates that after a certain professional year, the operational 
information cannot be recalled by the teachers. It can be said that this is due to the fact that teachers do not renew their knowledge of the field.

The above example question is provided by Uca (2010, p. 29) in explaining the operation priority rule in his master's thesis. However, in the study, the result was sahred by making mistakes while solving the question 21 . This also showed that mistakes can be made even in academic studies related to the priority of the operation.

\section{Conclusions about the Fifth Question}

In the fifth sub-problem of the study, an open-ended question was posed: "If a student who is on the 6th grade without knowing the subject of integers was asked to give an answer to "3-5 + 7" while operation priority is being presented and if the student said "this is faulty because the larger number cannot be subtracted from the smaller one", how would you answer, how would you explain the way to the solution to this problem?". The answers given by the participants were shared in written form, respectively. Some participants announced that the issue of integers needs to be internalized and that they will be presented with this in the future, while some others articulated that they will teach the signs and explain the solution to the problem. When the sixth-grade curriculum is analyzed, operation priority acquisition is presented in the first unit as follows:

"M.6.1.1.2. It takes four operations with natural numbers, taking into account the operation priority."

However, on the sixth grade, the acquisition of integers subject comes after the operation priority:

\section{"M.6.1.4.1. Recognizes integer numbers and shows the number line."}

In view of the above achievements, it is appropriate for the participating teachers to say that after learning the subject of integers, such questions can be solved. Likewise, this situation should be considered while preparing the curriculum. Explicitly, presenting operation priority subject after integer subject will eliminate this confusion among students. Otherwise, teachers who face such questions will have to teach the subject of integers. The results of the study of Yenilmez (2018) concentrating upon the difficulties faced by the sixth grade students in terms of operation priority support the findings of this study. Similarly, it was revealed that the students were quite misled about the operation priority and that the subject was not fully comprehended by the students. With the change, the subject of integers is included in the curriculum on the 7th grade. Explaining operation priority without learning integers, shows that it cannot be understood well by the students.

\section{Suggestions}

When the results of the research were examined, it was found that teachers did not have enough information about the operation priority. In particular, it is seen that the relatively new teachers in the profession do not have enough expertise in this field. To that end, more importance to the subject can be attached by asking questions in the field knowledge (expertise) examinations of newly graduated teachers. Lastly, these books can be studied and examined by teachers especially during the seminar periods at the beginning of the year.

In this study, one of the points emphasized is the conceptual information on the basis of the 
operation priority in arithmetic operations. One of the points emphasized is, in arithmetic operations, in fact, conceptual information lies at the basis of the operation priority. Hence, provided teachers learn the logic of the operation priority with the Peano Axiom, that is, conceptually, it can be learned and thusly taught as desired. The teacher, once knows the general logic behind the things, does not easily forget about the subject despite the years gained in the profession.

After certain professional experience, teachers gave almost no correct answer to the operation priority. This is a sign that they forgot the information they had beforehand. In that case, teachers need to update themselves.

In the books of the Ministry of National Education, there are inconsistencies between the information given on the priority of the operation. For example, in the 5th grade mathematics textbook published in the 2018-2019 academic year, it is pinpointed that the operation is primarily done in parentheses, in the 6th grade mathematics textbook, it is underlined that exponential operations will be performed before parentheses. However, scientific research on operation priority has standardized the operation priority as follows: "First, expressions in parentheses are made; then Exponential Expressions, then Multiplication and Division; the latest addition and subtraction operations are performed from left to right." (Öksüz, 2009). In this case, consistency should be the main concern in the books of the Ministry of National Education to be prepared and the operation priority should be presented in this order.

The fact that the graduates of the Faculty of Education appear to know the issue of operation priority better than the other faculty graduates, in the following years, secondary school mathematics teachers should completely be the graduates of the Faculties of Education. In other words, the Ministry of National Education should not allow the graduates of different faculties to become secondary school mathematics teachers.

Since this study is a qualitative one, similar studies can be conducted using quantitative research methods. The study can be expanded by selecting samples larger than the sample of this study. Teachers can talk to each other and discuss the pros and cons of the topic. In this way, expertise will improve.

As a result of the research, it was revealed that the teachers who started the profession new had shortcomings about the operation priority. Therefore, while teaching conceptual information at the university, the proof of the operation priority can be presented by teaching peano axiom.

Activities such as conferences, symposiums can be organized so as to increase the knowledge levels of teachers about the priority of the operation and active participation in these programs can be ensured.

Out of 1.5 million students taking the university exam, about 600 thousand answered the question of $80-(12+3+8)$ incorrectly, and on the basis of these shortcomings, it should not be overlooked that teachers have shortcomings about the subject. It would be fair to state that although instruction comes through a structured education system, it is still witnessed that teachers teach in traditional methods. In this regard, teachers should be given seminars and the new system should be fully implemented.

The mnemonic device: "Parayı (Parantheses) Üstünde (Exponential) Bulan (Division) Çabucak (Multiplexing) Tatile (Addition) Çıkar (Subtraction)") developed by Öksüz (2009) where the first letters stand for the clues for the operation priority can be included in 
mathematics textbooks. In this way, the operation priority can be coded as ParenthesesExponential-Division-Multiplication-Addition-Subtraction (PEDMAS). This can attract students' attention to the learning of the subject and the knowledge can become more permanent.

\section{Acknowledgement}

This article was produced from the master's thesis titled "Determining the Mistakes of Secondary School Mathematics Teachers on Operation Priority". A part of this study was presented as a summary at ICLEC 2019 symposium.

\section{References}

Akkan, Y., Çakıroğlu, Ü. \& Güven, B. (2008). Some Errors and Misconceptions Students Have in the Field of Algebra Learning. Journal of Educational Sciences \& Practices, 7(13), $55-74$.

Brown, J. S. \& Burton, R. R. (1978). Diagnostic Models for Procedural Bugs in Basic Mathematical Skills. Cognitive Science, 2,155-192.

Büyüköztürk, Ş. Kılıç, Ç. E. Akgün, Ö. E. Karadeniz, Ş. \& Demirel. F. (2012). Scientific Research Methods. Ankara: Pegem Akademi Publications.

Cengiz, N. (2013). Definitions and Historical Developments with Mathematical Concepts. Ankara: Pegem Akademi Publications.

Chick, H., L. \& Baker, M., K. (2005). Investigating Teacher's Responses to Student Misconceotions. In Chick, H. L. and Vincent, J. L. (Eds.). Proceedings of the 29 th Conference of the International Group for the Psychology of Mathematics Education (Vol.2, pp. 249-256). Melbourne: PME.

Dede, Y.\& Peker, M. (2007). Elementary School Students' Errors in Solving Problems Related to Pressure Subjects. Elementary Education, 6(1), 35-49.

Dinç Artut, P. \& Tarım, K. (2006). Elementary Students' Comprehension of Place Value Concept. Theory and Practice in Education, 2(1), 26-36.

Doğan, A. (2002). The mistakes primary grade students make in natural numbers during four operations. Unpublished Master Thesis, Gazi University, Institute of Educational Sciences, Ankara.

Ekiz, D. (2003). Introduction to Research Methods in Education: Methodologies of Qualitative, Quantitative and Critical Methods. Ankara, An1 Publishing.

Engelhardt, J. M. (1977). Analysis of Children's Computational Errors: A Qualitative Approach. British Journal of Educational Psychology, 47,149-154.

Govindan, N. \& Ramaa, S. (2013). Analysis of Errors Made by Children with Hearing Impairment. International Journal of Science and Research, 4(3), 201-208.

İlgün, Ş., Elmas, S., \& Küçük, S. (2017). Order of Priority in Arithmetic Operations. Journal of Bayburt Faculty of Education, 12(23), 253-270.

Kocaoğlu Er, F. S. (2016). Primary Education Mathematic Teachers' Opinions on 5 th and 6th Grade Course Books. Gazi University, Institute of Educational Sciences, Ankara.

Kubanç, Y. (2012). The Challenges Faced by 1., 2. and 3. Grade Primary School Students in the Process of Solving Mathematical Verbal Problems and Solution Recommendations. Firat University, Institute of Educational Sciences, Elazı̆

Öçal, M.F., İpek, A.S., Özdemir, E., Kar, T. (2018). Investigation of Secondry School Students' Problem Forming Skills for Arithmetic Expressions in the Context of Priority of Operation. Turkish Journal of Computer and Mathematics Education Vol.9 No.2 (2018), 170-191 
Öksüz, C. (2009). Teaching the "Order of Operations". Elementary Education, 8(2), 306-312.

Patton, Q. M. (2014). Qualitative Research and Evaluation Methods. (Translated by. Bütün, M. \& Demir, S. B.). Ankara: Pegem Akademi.

Süzen, A.B. (2019). Determination of the Errors of the Middle School Mathematics Teachers on the Transaction Priority. Firat University, Institute of Educational Sciences, Elazığ.

Tavşanc1l, E. \& Aslan, E. (2001). Content Analysis and Application Examples for Verbal, Written and Other Materials. İstanbul: Epsilon Publication.

Tutak, T., \& Güder Y. (2012). The Opinions of the Primary 5th Grade School Teachers 'Views about Mathematics Textbook. Dicle University Journal of Ziya Gökalp Faculty of Education, 19, 16-28.

Uça, S. (2010). A New Approach When Comprehending the Order of Operations in Mathematics Instruction: Mnemoni. Unpublished Master Thesis, Adnan Menderes University, Institute of Social Sciences, Aydın.

Ülger, A. (2005). A Brief History of Mathematics. University and Society, 5(1), 8.

Varol, F. \& Kubanç, Y. (2015). Requiring Students to Beat the Experienced by the Verbal and Arithmetic Division Operation Investigation of Problems. Ondokuz Mayls University Journal of Faculty of Education, 34(1), 99-123.

Yenilmez, K. (2018). Sixth Grade Students' Understanding Level of Some Basic Mathematics Concepts. Journal of Research in Education and Training 7(2), 275-292.

Yıldırım, A. \& Şimşek, H. (2008). Qualitative research methods in the social sciences. Ankara: Seçkin Publishing. 